\title{
Utilization of Cocoa Bean Shell as a Paper-Based Food Packaging and a Method to Improve Surface Hydrophobicity
}

\author{
Tamrin ${ }^{1, *}$, Sri Rejeki ${ }^{1}$, RH Fitri Faradilla ${ }^{1}$, Mariana $\mathrm{M}^{1}$, \\ Muhammad Nuh Ibrahim ${ }^{1}$, Irnawati ${ }^{1}$ \\ ${ }^{I}$ Department of Food Science and Technology, Faculty of Agriculture, Universitas Halu Oleo, Kendari, Indonesia \\ *Corresponding author. Email: tamrin@uho.ac.id
}

\begin{abstract}
Cocoa bean shell was utilized to develop a paper-based food packaging material. This cocoa bean shell paper was foldable and relatively strong. The papers also had antimicrobial and antioxidant properties that made these papers potential materials for active packaging. However, the papers were highly hydrophilic, which limits their application as food packaging. This research explored the coating process with carnauba wax to improve the cocoa bean shell paper surface hydrophobicity. Carnauba wax was organic material that was relatively safe to be used in food products. We found that a number of dipping and concentration of coating greatly affected the contact angle of the papers. The coating treatment increased contact angle from $40.50^{\circ}$ for uncoated papers to $126.99^{\circ}$ for carnauba wax coated papers. The coating application also did not affect the mechanical properties of the paper. This research showed that the application of carnauba wax could produce hydrophobic paper from the cocoa bean shell.
\end{abstract}

Keywords: cocoa bean shell paper, carnauba wax, hydrophobic

\section{INTRODUCTION}

Cocoa bean shell as a by-product of chocolate manufacture counts about $11-20 \%$ of the bean[1]. This material is the potential to be utilized as a food packaging material considering its antioxidant and antimicrobial properties[2][3].

Our research group has produced papers from cocoa bean shell and the results were promising since the antioxidant, and antimicrobial properties of the bean shell were preserved. However, the papers were hydrophilic since they mainly consisted of polysaccharides with polar hydroxyl groups.

The coating technique has been used for a long time to improve the surface properties of a paper. There is a wide range of substance that can be used for this purpose, such as polyethylene, polyvinyl alcohol, rubber latex, and fluorocarbon [4]. However, synthetic and petroleum-based coatings are not biodegradable and may pose some risk to human health.

Many research papers have reported the use of natural polymer and ingredients as a coating material[4]. One example is carnauba wax, a plant-based wax. Reference [5] reported that the carnauba wax can be used to improve the hydrophobicity and permeability of the hydrophilic paper made of cellulose and chitosan. A similar finding was also reported in [6], where the permeability to water vapor reduced due to the coating treatment using carnauba wax. Reference [7] successfully produced a superhydrophobic paper by coating with a mixture of carnauba wax and beeswax.

Due to the potential of carnauba wax as a natural coating material, in this paper, we will report the utilization of carnauba wax as a coating material in cocoa bean shellbased paper. The effect of this coating on the water contact angle and mechanical properties of the paper were evaluated.

\section{METHODS}

\section{A. Materials}

Cocoa bean shell was sourced from PT KallaKakaoIndustri, Kendari. Coating material was carnauba wax and n-hexane was used as the solvent.

\section{B. Coating of Cocoa Bean Shell Paper with Carnauba Wax}

Carnauba wax $(1,2$, and $3 \mathrm{~g}$ ) was diluted in $10 \mathrm{~mL} \mathrm{n-}$ hexane at $100{ }^{\circ} \mathrm{C}$. The solution was cooled down to $60{ }^{\circ} \mathrm{C}$ prior coating. The cocoa bean shell papers were then dipped in warm carnauba wax solution for $10 \mathrm{~s}$. The papers were air-dried. Dried coated papers were dipped again in the coating solution and dried. This procedure was repeated four times so that three types of coated paper were obtained based on the amount of dipping cycle $(2 x, 3 x$, and $4 x)$. Samples were coded with the format of C\#D\#, where C was the amount of carnauba wax in $10 \mathrm{~mL}$ hexane $(1,2$, or $3 \mathrm{~g})$ and $\mathrm{D}$ was the number of dipping cycle $(2,3$, or $4 \mathrm{x})$. 
Smooth Surface

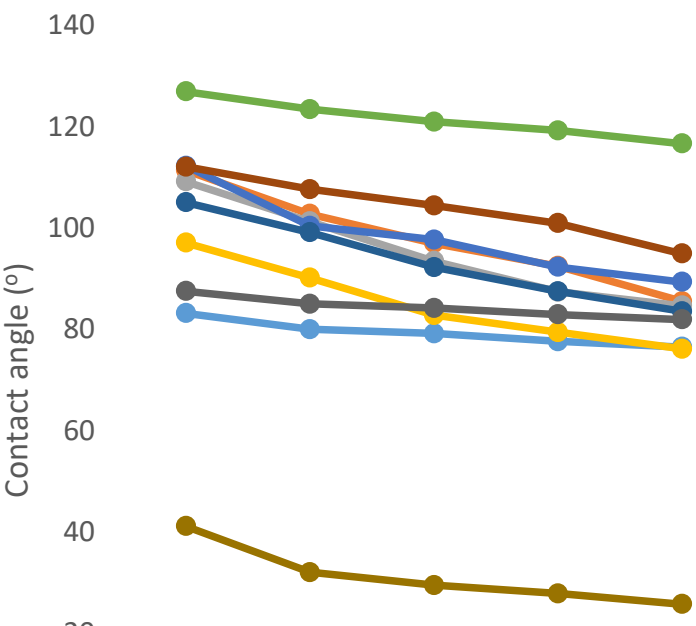

20

$$
0
$$

$\begin{array}{ccccc}0 & 30 & 60 & 90 & 120 \\ & & \text { Time }(\mathrm{s})\end{array}$

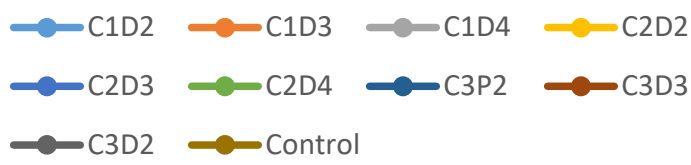

Figure 1. Contact angle of papers on the smooth surfaces.

Control was the cocoa bean shell paper without coating treatment.

\section{Analysis}

The hydrophobicity of the paper was evaluated by measuring the paper contact angle. Water was used as the liquid phase and the contact angle was determined every 30 $\mathrm{s}$ for two minutes. Corel Draw X7 was used to measure the angle. Data were statistically analyzed using Two-Way ANOVA with statistic software developed by[8].

Paper with the highest contact angle was then further analyzed for their morphological and mechanical properties. The cross-section of the paper was visualized using a Scanning Electron Microscope (SEM) with gold coating. The mechanical properties were determined using the Tensile Test.

\section{RESULTS AND DISCUSSION}

\section{A. Paper Contact Angle}

The water contact angle of the papers were evaluated for both side of papers. Papers were made by casting the cocoa bean shell pulp on plastic Petri dishes. The surface of the paper that contacted with the bottom of the dish had a smooth and flat texture. On the other hand, the side of the paper that did not directly touch the dish had a rough surface. This difference in the surface roughness might affect the interaction between paper and coater and also the contact angle of the paper. Reference [9] reported that the
Rough Surface

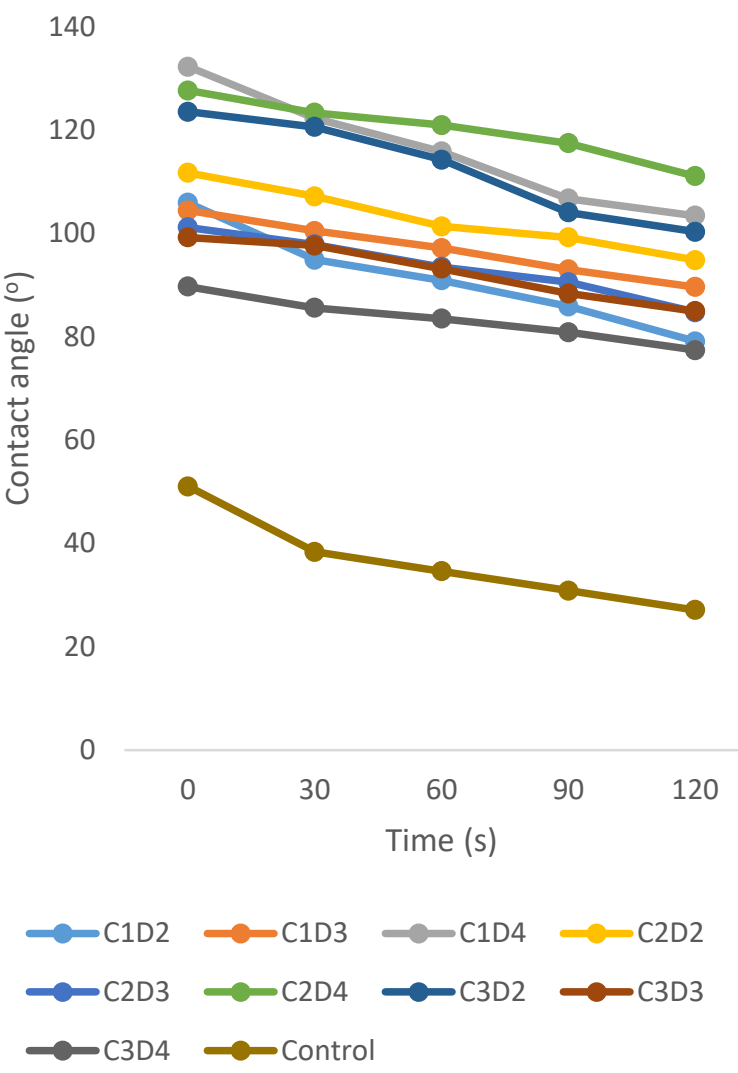

Figure 2. Contact angle of papers on the rough surfaces.

surface roughness of a material affects the contact angle, where the contact angle of the rough surface is generally higher than the smooth surface. Even so, this is not always the case since the type of roughness also influences the contact angle [10]. Therefore, the contact angle of both sides was determined and are presented in Figure 1and 2. In general, when all contact angle values were averaged, the contact angle of the rough surface was slightly higher than the smooth surface. The average of the contact angle of the smooth surface was $98.64^{\circ}$ at $0 \mathrm{~s}$ and $85.26^{\circ}$ at $120 \mathrm{~s}$, while the average of contact angle of the rough surface was $104.66^{\circ}$ at $0 \mathrm{~s}$ and $85.26^{\circ}$ at $120 \mathrm{~s}$.

The contact angle was greatly affected by the coating treatment. The control paper had a contact angle of $46.12^{\circ}$ at $0 \mathrm{~s}$ and $26.47^{\circ}$ at $120 \mathrm{~s}$, which indicated that the paper was hydrophilic. The coating treatment increased the contact angle dramatically, with the highest contact angle was higher than $120^{\circ}$ at $0 \mathrm{~s}$. This shows that the carnauba wax has a potential as a coating material to produce hydrophobic cocoa bean shell paper.

Figure 1 and Figure 2 also show that the concentration of the carnauba wax and the number of dipping cycle influence the efficacy of the coating treatment. However, their effect should not be seen individually. The interaction of these two variables was statistically significant $(p<0.05)$, while the effect of the individual variable was not significant $(p>0.05)$. Figure 3 illustrates the effect of the interaction of the concentration of the carnauba wax and the 
number of dipping cycles on the paper contact angle. The number of the dipping cycle was positively correlated to the contact angle value when the carnauba wax concentration was low. However, the number of dipping cycle negatively affected the contact angle when the concentration of carnauba wax was high $(3 \mathrm{~g} / 10 \mathrm{~mL})$. We observed that

when carnauba wax was used in high concentration, the paper became oily and the wax did not strongly attach on the paper surface. This might be the reason for the reduction in contact angle.



Figure 3. The effect of interaction between concentration of the carnauba wax and the number of dipping cycle on the paper contact angle

The optimum treatment was on sample C2D4, where the concentration of carnauba wax was $2 \mathrm{~g} / 10 \mathrm{~mL}$ and number of dipping cycle was four times. Contact angle of this paper was still higher than $110^{\circ}$ after 2 minutes observation.

\section{B. Morphology and Mechanical Properties of the Hydrophobic Paper}

The cross-section of the control paper was compared with the C2D4 paper using SEM (Figure 4a and b). There was no distinctive difference between the picture of the control cross-section and the C2D2 cross-section. This indicates that the ratio between coating thickness and paper thickness was very small. The thickness of the paper was approximately $1.51 \mathrm{~mm}$. when the surface of the C2D2 paper was captured in higher magnification, the presence of coating could be seen (Figure 4c). The carnauba wax created a stringy thin layer.

It is also worth noting that although the coating was thin, it created a white color on the paper surface. This may not be a problem with a bleached paper, but since cocoa bean shell paper was brown, the white color may cause a less appealing color to the paper. Further study is needed to counter this problem. Method of [7] might be adopted for this purpose. They used the combination of carnauba wax and beeswax in a surfactant to produce a transparent coating with the superhydrophobic property. a)
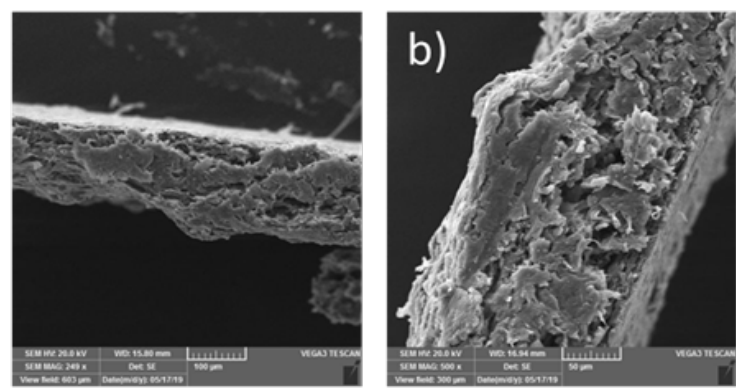

c)

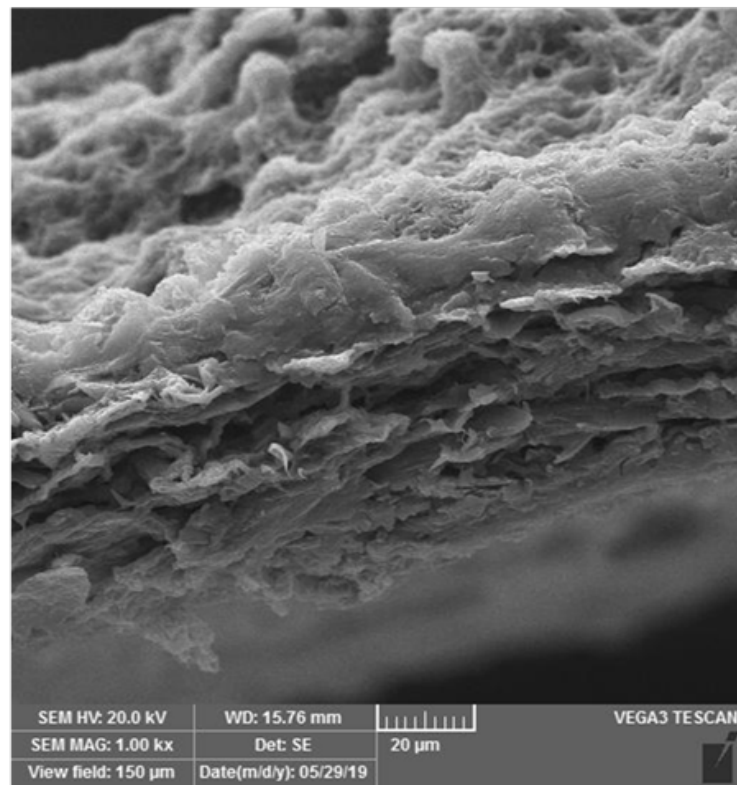

Figure 4. SEM image of a) cross section of control paper; b) cross section of C2D4; and d) closer look at the cross section and surface of C2D4

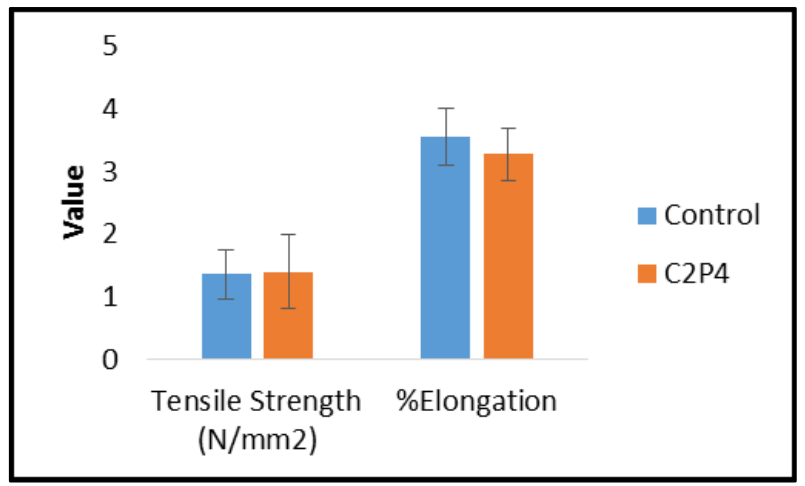

Figure 5. Mechanical properties of the sample papers

The mechanical properties of the paper were not affected by the coating treatment as can be seen in Figure 5. Both tensile strength and percent elongation of the control paper and $\mathrm{C} 2 \mathrm{P} 4$ paper were not statistically significant $(\mathrm{p}>0.05)$. This was favorable since in some cases, the coating material can cause an adverse effect of the strength and flexibility of paper or thin films. For example, [6] found that the coating with carnauba wax caused adverse effects on tensile strength and elongation of a paper. 


\section{CONCLUSION}

The application of carnauba wax as a coating agent successfully increased the contact angle of cocoa bean shell paper.The paper, which was initially hydrophilic with a contact angle of $46.12^{\circ}$, became hydrophobic after coating with contact angle of $127.68^{\circ}$. Interaction between the concentration of carnauba wax and the number of dipping cycle significantly affected $(p<0.05)$ the contact angle of the paper. The mechanical properties of the paper were not affected by the coating treatment. Tensile strength and $\%$ elongation of the paper relatively remained the same even after coating.

\section{ACKNOWLEDGMENT}

This research is funded by Ministry of Research Technology and Higher Education of Republic of Indonesia under the Program Insentif Riset Sistem Inovasi Nasional (INSINAS) scheme.

\section{REFERENCES}

[1] A. Bart-Plange and E. A. Baryeh, "The physical properties of Category B cocoa beans," J. Food Eng., vol. 60, no. 3, pp. 219-227, 2003.

[2] J. Nsor-Atindana, F. Zhong, K. J. Mothibe, M. L. Bangoura, and C. Lagnika, "Quantification of total polyphenolic content and antimicrobial activity of cocoa (Theobroma cacao L.) bean shells," Pakistan J. Nutr., vol. 11, no. 7, p. 574, 2012.

[3] D. C. G. Okiyama, S. L. B. Navarro, and C. E. C. Rodrigues, "Cocoa shell and its compounds:
Applications in the food industry," Trends Food Sci. Technol., vol. 63, pp. 103-112, 2017.

[4] K. Khwaldia, E. Arab-Tehrany, and S. Desobry, "Biopolymer coatings on paper packaging materials," Compr. Rev. food Sci. food Saf., vol. 9, no. 1, pp. 82-91, 2010.

[5] S. Despond, E. Espuche, N. Cartier, and A. Domard, "Barrier properties of paper-chitosan and paper-chitosan-carnauba wax films," J. Appl. Polym. Sci., vol. 98, no. 2, pp. 704-710, 2005.

[6] K. Khwaldia, M. Linder, S. Banon, and S. Desobry, "Effects of mica, carnauba wax, glycerol, and sodium caseinate concentrations on water vapor barrier and mechanical properties of coated paper," J. Food Sci., vol. 70, no. 3, pp. E192-E197, 2005.

[7] W. Zhang, P. Lu, L. Qian, and H. Xiao, "Fabrication of superhydrophobic paper surface via wax mixture coating," Chem. Eng. J., vol. 250, pp. 431-436, 2014.

[8] I. E. Holliday, "Two-Way ANOVA (v1.0.6) in Free Statistics Software (v1.2.1), Office for Research Development and Education.” 2019.

[9] R. H. Dettre and R. E. Johnson Jr, "Contact angle hysteresis: II. Contact angle measurements on rough surfaces," ACS Publications, 1964.

[10] J. J. Bikerman, "The Surface Roughness and Contact Angle.," J. Phys. Chem., vol. 54, no. 5, pp. 653-658, 1950 . 